\title{
AVALIAÇÃO DA EDUCAÇÃO PÚBLICA EM MUNICÍPIO POLO DA ZONA DA MATA MINEIRA
}

\section{Aline Machado Barbosa Franklin ${ }^{1}$ \\ Lidiane Espindula²}

Resumo: Esta pesquisa apresenta parte de um estudo acerca da educação pública do Município de Manhuaçu-MG, um dos elementos que compõem a avaliação base para a revisão do Plano Diretor do município (em andamento). Tendo em vista o crescimento acelerado do processo de urbanização das cidades brasileiras, principalmente a partir da segunda metade do Séc. XX, diversos polos se formaram, entre eles em Manhuaçu, que atende cerca de trinta municípios da região. A partir de pesquisas na Secretaria de Educação do município, visitas in loco nas unidades de ensino e consulta de dados estatísticos, o estudo apresenta situação aceitável no atendimento dado à educação aos habitantes da Manhuaçu e região.

Palavras-chave: Plano Diretor; Unidades de Ensino; Qualidade de Vida; Manhuaçu.

\footnotetext{
1 Arquitetura e Urbanismo/Faculdade de Ciências Gerenciais de Manhuaçu - FACIG, Brasil. E-mail: alinemachadobarbo@hotmail.com.

2 Arquitetura e Urbanismo/Faculdade de Ciências Gerenciais de Manhuaçu - FACIG, Brasil. E-mail: espindulaprojetos@gmail.com.
} 